\title{
DIREITO EMPRESARIAL E A EVOLUÇÃO DO CONCEITO DE JUSTIÇA ${ }^{1}$
}

\author{
Dalton João Atanasio de Farias ${ }^{2}$ \\ Maria Darlei Mafioletti ${ }^{3}$ \\ Ruthnéa Bernadete Fernandes Fritzen ${ }^{4}$ \\ Simone Morsoletto Primon ${ }^{5}$ \\ Ana Lilian Villvock Azevedo ${ }^{6}$
}

Recebido em 09/12/2020

Aceito em 21/12/2020

\section{RESUMO}

Este artigo tem por escopo demonstrar uma visão histórica do Direito Empresarial, sob a perspectiva da justiça social. Sua finalidade é discorrer o estudo em questão com a leitura interdisciplinar sugerida pelos professores responsáveis da Instituição de Ensino Universidade Alto Vale do Rio do Peixe. Nesse sentido, será exposto que o Direito Empresarial, tal qual outras áreas jurídicas, deve se valer também da sociedade, visto que o interesse social é de suma importância para o desenvolvimento jurídico da empresa e da sociedade em geral. Assim, vêse que as evoluções sociais fazem com que as empresas sigam tais mudanças, sob pena de se tornarem obsoletas e fora dos padrões. Destarte, destacar-se-á sobre a responsabilidade da empresa frente às expectativas sociais e ambientais. E, para tanto, será usado o método dedutivo/qualitativo, sendo usado bibliografias de diversas épocas, afim de elucidar a trajetória do Direito Comercial desde sua origem até os dias atuais.

PALAVRAS CHAVES: Direito Empresarial, Sociedade e Evolução.

\section{DERECHO EMPRESARIAL Y LA EVOLUCIÓN DEL CONCEPTO DE JUSTICIA}

\section{RESUMEN}

Este artículo tiene como objetivo demostrar una visión histórica del derecho empresarial, desde la perspectiva de la justicia social. Su propósito es discutir el estudio en cuestión con la lectura interdisciplinaria sugerida por los profesores responsables de la Institución Docente Universidad Alto Vale do Rio do Peixe. En este sentido, se expondrá que el Derecho Societario, al igual que otras áreas jurídicas, también debe utilizar la sociedad, ya que el interés social es de suma importancia para el desarrollo jurídico de la empresa y de la sociedad en general. Así, se puede ver que los desarrollos sociales hacen que las empresas sigan tales cambios, bajo pena de volverse obsoletos y fuera de los estándares. Así, destacará sobre la responsabilidad de la empresa ante las expectativas sociales y medioambientales. Y, para ello, se utilizará el método deductivo / cualitativo, utilizándose bibliografías de diferentes épocas, con el fin de dilucidar la trayectoria del Derecho Mercantil desde su origen hasta la actualidad.

Palabras clave: Derecho empresarial, sociedad y evolución.

1 Artigo Científico apresentado como requisito para conclusão da Leitura Interdisciplinar, para complementação de nota M2, orientado pela professora Ana Lilian Villvock Azevedo.

2 Acadêmico da $9^{\text {a }}$ fase do Curso de Direito da Universidade Alto Vale do Rio do Peixe/Fraiburgo - SC.

3 Acadêmico da $9^{\text {a }}$ fase do Curso de Direito da Universidade Alto Vale do Rio do Peixe/Fraiburgo - SC.

4 Acadêmico da $9^{\text {a }}$ fase do Curso de Direito da Universidade Alto Vale do Rio do Peixe/Fraiburgo - SC.

5 Acadêmico da $9^{\text {a }}$ fase do Curso de Direito da Universidade Alto Vale do Rio do Peixe/Fraiburgo - SC.

6 Orientadora e Professora da Disciplina de Direito Empresarial I. 


\section{INTRODUÇÃO}

O Direito Empresarial, tal qual outras áreas jurídicas, não tem como estar distante da sociedade, bem como, do seu constante desenvolvimento. Assim, a cada dia surgem novas perspectivas e exigências para as quais a empresa deve estar preparada, ou adaptar-se para não se tornar obsoleta, ou mesmo, acabar por ser rechaçada por seus colaboradores. A empresa, sociedade, como um todo, está cada dia mais exigente no que tange à responsabilidade da empresa, para que atenda às expectativas tanto sociais, como ambientais, sendo o lucro, muitas vezes, reflexo de tais atitudes. Assim, pretende-se, nesse estudo, discorrer sobre a evolução do Direito Empresarial na sociedade brasileira, bem como explorar os desafios que se moldam gradualmente no cenário atual.

Primeiramente procurar-se-á traçar uma retrospectiva histórica, a fim de perceber a evolução do Direito Empresarial no decorrer da história da humanidade. Nesse exame pretende-se também elucidar acerca da Teoria dos Atos do Comércio e da Teoria da Empresa, percebendo os liames que circundam a metamorfose pela qual passou o Direito empresarial, com a mudança do destaque do personagem do empresário para a atividade que desempenha.

Após, far-se-á uma análise acerca da questão da Responsabilidade Social Empresarial, bem como das circunstâncias que envolvem a função social da empresa num Estado Democrático de Direito. Nesse contexto, discorrer-se-á também sobre a questão da sustentabilidade ambiental no Direito Empresarial, uma vez que esta, inserida em um contexto social abrangente, não há como permanecer díspar aos compromissos ambientais. Por fim, explorar-se-á a respeito do Direito Empresarial no cenário atual, suas regulamentações e compromissos inescusáveis.

\section{UMA BREVE RETROSPECTIVA DO DIREITO COMERCIAL}

O comércio existe desde que o homem sentiu necessidade de negociar um com o outro, com o intuito de atender necessidades momentâneas, sabendo que seria a única forma de conseguir satisfazê-las. Assim, gradativamente, houve a emergência de regulamentar esse intercâmbio de bens, com a devida elaboração de normas de conduta para a relação pacífica na troca de mercadorias e produtos. (MIRAGEM, 2004).

Nessa circunstância surge o Direito Comercial, o qual, após passar pela Antiguidade, desde os fenícios, às civilizações gregas e romanas, chegou à Idade Média, com uma Europa tomada pela miséria econômica, que vê no comércio um meio tanto para gerar, quanto para multiplicar riquezas. E assim, o Direito Comercial veio para regulamentar as operações de comércio, e se expandiu ao alcance do desenvolvimento econômico, em um sistema menos formal (MIRAGEM, 2004).

Destarte, partilham do mesmo entendimento, no que tange ao nascimento do Direito 
Comercial, os juristas BENSOUSSAN; BOITEX (2018, p. 7):

\begin{abstract}
É certo que o comércio é praticado desde a Antiguidade. A partir do momento em que as sociedades ultrapassaram a etapa de produzir para sua mera subsistência e passaram a obter excedentes, surge a prática das trocas de produtos e, com ela, a necessidade de se regular estas mesmas trocas. O comércio nasce pelo escambo, pela troca de bens que interessam ao outro.
\end{abstract}

Entende-se, contudo, que a origem do comércio se deu quando o próprio povo se viu obrigado trocar de mercadoria para satisfazer suas vontades e necessidades, visto que o que produzia não era suficiente para tanto. E, no entanto, já se precisavam estabelecer regras e validades para se efetuar o negócio com justiça.

\title{
2.1 A HISTÓRIA DO DIREITO COMERCIAL NO BRASIL
}

Não obstante, no Brasil, pode-se afirmar que o surgimento do Direito Comercial, estava vinculado à situação política da época de seu descobrimento. Ou seja, no Período Colonial, as relações de comércio eram estabelecidas com Portugal, as regras, portanto, eram geridas pela tradição jurídica portuguesa (MIRAGEM, 2004). Nesse contexto, em terras tupiniquins, o Direito Comercial passou pelas Ordenações Afonsinas, com subsidiariedade do direito canônico, em seguida foram substituídas pelas Ordenações Manuelinas, mantendo, a inspiração nas fontes romanas. Após, com as Ordenações Filipinas, que geriram o Brasil, ainda após a independência política de 1822, passou a ser tratado diretamente sobre matéria comercial em todos os âmbitos jurídicos (MIRAGEM, 2004).

A partir de então, alterações foram surgindo por décadas, até a promulgação da Codificação Portuguesa em 1833, inspirada no código francês e espanhol, e também no projeto do Código Italiano. Posteriormente, foram surgindo leis extravagantes a fim de regular necessidades e conflitos em abstrato, quais sejam, "sociedades anônimas (1867)", "marcas e patentes (1883)", o que, gerou a necessidade da elaboração de um novo código, o qual foi promulgado em 1888 (MIRAGEM, 2004).

O Código Comercial de 1888, marcou a história brasileira, principalmente sobre o Direito Empresarial, isso porque influenciou no desenvolvimento da economia e do comércio brasileiro. Observa-se que, com a vinda das cortes portuguesas, em 1808, e a consequente elevação do Brasil a Reino Unido de Portugal e Algarves, houve a liberação do comércio marítimo, por meio da Carta Régia de 1808. Ganha destaque esse acontecimento porque além da abertura dos portos às nações amigas, também fomentou a atividade fabril e manufatureira (Alvará de $1^{\circ}$ de abril), a liberação do comércio e da Indústria e a posterior criação da Real Junta de Comércio, Agricultura, Fábricas e Navegação. Ainda, o alvará de 12 de outubro do mesmo ano possibilitou a criação da primeira instituição bancária 
brasileira: o Banco do Brasil (MIRAGEM, 2004).

Mesmo após a independência política do Brasil, em 1822, uma lei (de 20 de out. de 1823) determinou que no Brasil se mantivesse em vigência as leis portuguesas. Mais tarde, Silva Lisboa foi designado a elaborar o Código Comercial Brasileiro, mas as tentativas de elaboração apenas se ampliaram em 1832. Veja-se que em 1834 foi enviado o projeto à Câmara dos Deputados, sendo promulgado, após 16 anos de tramitação, pela lei n556 o Código Comercial Brasileiro, em 1850. (MIRAGEM, 2004).

E assim, paulatinamente, outras legislações foram sendo criadas ou reformadas, com o intuito de abranger todas as circunstâncias atinentes ao Direito Comercial, surgindo em 1911 a necessidade de um novo Código Comercial em 1911, através de decreto anterior autorizando a reforma. Esta, se inicia em 1936, porém, é interrompida devido à instituição do Estado Novo e fechamento do Congresso Nacional (MIRAGEM, 2004).

Como visto, a evolução do Direito Comercial passou por vários eventos, alguns devidamente documentados, outros nem tanto, mas que deixaram indícios de negociações comerciais. Dentre estes, cabe ressaltar uma ordem cronológica e relembrar alguns já mencionados, sendo estes: primeiros escritos jurídicos entre a Mesopotâmia e Egito; preceitos morais e jurídicos da Bíblia, legado pelos hebreus; o Código de Hamurab; atividades empreendedoras na Grécia e Roma antigas; o reestabelecimento do comércio europeu com os territórios asiáticos e africanos. O Brasil, como já mencionado, teve influência da monarquia portuguesa, a qual marcou sua era comercial, com o Alvará de 1785, extinguindo a manufatura têxtil com exceção dos panos grossos usados para roupas de escravos; abertura dos portos a fim de garantir sua sobrevivência em 1808; as ordenações filipinas e a Lei da Boa Razão (1769), vigoraram até a elaboração do Código Comercial de 1850; relação ainda, com o Código Civil de 1916; Junta comercial em 1808; atos do comércio com o regulamento $\mathrm{n}^{\circ} 737$ em vigor até 1930; industrialismo marcado em 1870; reconhecimento das sociedades anônimas com o Decreto $^{\circ}$ 575; por derradeiro, a aprovação do Código civil de 2002, o qual se identifica com o sistema italiano no que diz respeito à teoria da empresa, e continuou com uma parte do direito marítimo do código comercial antigo. Hoje, no Brasil, é a atividade empresária que orla o direito comercial, constituindo, o conceito fundamental para esse ramo jurídico, abrangendo a atividade de distribuição e produção, corroborando com esse conceito também atribuído pelo Código de Defesa do Consumidor (Lei $\mathrm{n}^{\circ}$ 8.078/90) (BENSOUSSAN; BOITEX, 2018).

\subsection{AS CORPORAÇÕES DE OFÍCIO}

Ainda na baixa Idade Média, com o fim das invasões, houve o renascimento urbano e o 
aparecimento das feiras medievais. Com o aumento da segurança, nesse tempo, ocorreu a melhoria das técnicas agrícolas, o que permitiu um aumento da produção e a consequente geração de excedentes os quais seriam passíveis de troca. (BENSOUSSAN; BOITEX, 2018).

Os Comerciantes deixam de ser meros intermediadores de mercadorias e passam a promover artesãos locais, começando a se utilizar de empregados e auxiliares. A ausência de regulamentação adequada, bem como as imposições do Direito Canônico, que não permitiam o lucro e a usura, fez com que os comerciantes medievais se organizassem em associações de acordo com o trabalho desenvolvido, surgindo um direito de produção autônoma, feito por e para os comerciantes (BENSOUSSAN; BOITEX, 2018). Esse direito foi chamado de jus mercatorum, no qual:

\begin{abstract}
Os comerciantes e artesãos se agrupavam nas chamadas Corporações de Ofício, ou guildas, que, à falta de uma centralização política, passaram a formular normas e consolidar costumes observados nas práticas comerciais, que aplicavam aos seus próprios membros, por meio dos tribunais consulares. $\mathrm{O}$ ingresso em uma corporação era feito através de um juramento (matricula, precedente remoto do que viria a ser o registro de empresas) em que o comerciante se comprometia a observar os estatutos, obedecer aos cônsules e adotar uma postura ordeira. A matricula lhes conferia a proteção da corporação - como hoje o registro garante direitos ao empresário, que se torna um empresário regular (BENSOUSSAN; BOITEX, 2018, p.26).
\end{abstract}

Nessa época, então, existia um direito aplicado aos membros das corporações, como um direito de classe, essencialmente costumeiro e consuetudinário, ditado pela eficácia da prática comercial. Não havia mediação direta pela sociedade política, sendo imposto por uma classe (BENSOUSSAN; BOITEX, 2018).

\title{
2.3 TEORIA DOS ATOS DO COMÉRCIO
}

Com o passar do tempo percebeu-se que surgia a necessidade de aplicação do direito a pessoas que não se dedicavam ao comércio profissionalmente, mas que faziam transações comerciais. Para isso, o direito aplicado apenas aos membros das corporações de ofício, passou a não atender às necessidades contextuais (BENSOUSSAN; BOITEX, 2018).

Além de que, por volta do século XVI, surgem os Estados Nacionais Europeus, e a consequente necessidade de unificação das normas jurídicas sobre as atividades econômicas. Assim, as legislações de cunho privado, passam a ser essencialmente públicas, e, com isso, os estatutos das corporações necessitavam da aprovação real para se tornarem válidos. O rei outorga então a liberdade de comércio a todos os que se registram na corporação. (BENSOUSSAN; BOITEX, 2018).

Assim, passa-se para uma segunda fase do Direito Comercial, na qual:

A Revolução Francesa extinguiu as corporações de ofício (Lei Chapelier, sob o fundamento de que representavam o sistema de castas contrário à igualdade de todos os cidadãos), o que tornava difícil a identificação da figura do comerciante para a 
definição do âmbito de incidência do direito comercial. Estava superada a fase subjetiva. Mas é no início do século XIX, com o Código Civil francês de 1804 (Código Napoleão) e o Código do Comércio de 1807, que surge a chamada segunda fase do direito comercial, a fase objetiva. A existência dos dois Códigos levou à perda de unidade do direito privado e à necessidade de se estabelecer, de forma clara, critérios para delimitar a abrangência do Direito Civil e do Direito Comercial (BENSOUSSAN; BOITEX, 2018, p.28)

A partir de então inicia-se a fase objetiva do direito comercial, com Código Napoleão (1.804) e o Código do Comércio (1.807). Advindo desses dois códigos, os requisitos para os atos do comércio passaram a ser mais uno, respeitando a igualdade entre todos diante da lei. O Direito Comercial não podia distinguir pessoas e tratar com privilégios, seus critérios passaram a ser mais objetivos. É, nessa fase que o direito dos comerciantes passa a ser denominado direito dos Atos do Comércio, dando origem à “Teoria dos atos do comércio'. O direito comercial continuava a ser estatal, porém, com uma aplicação da classificação de atos com traços comuns, excluindo algumas atividades específicas que não condiziam com a comercialização em si. (BENSOUSSAN; BOITEX, 2018).

Com isso o legislador colocou comércio em âmbito mais dinâmico com adaptação e segurança jurídica. Contudo, a comparação do Código do Comércio (1807) com a evolução atual, traz conflitos no tratamento dos atos dos comerciantes e dos não comerciantes com o Código Civil. Visto que é a habitualidade que define a profissão do comerciante, entre os negócios com os não comerciantes, porém, conflitam-se entre si a jurisdição abrangente, pois as mudanças contidas nos atos de comércio alargaram a produção em série emergindo muito mais a quantidade de bens e serviços (BENSOUSSAN; BOITEX, 2018).

Nesse aspecto, Aziz (2017, n.p) traduz:

Nessa teoria, são considerados empresários aqueles que praticavam um ato de comércio e tinham a mercancia como profissão. Mas como o registro não era de fato obrigatório, e sim facultativo, um vendedor ambulante, por exemplo, era considerado empresário, já que praticava um ato de comércio e exercia a mercancia como profissão.

Em suma, a "Teoria dos atos de comércio", originada no Código Comercial de 1850, seguia um regime jurídico específico, diferenciando do que regia outras atividades econômicas. Atribui-se aos atos do comércio, características determinadas, indiferentemente de quem as pratica. Pois para configurar comércio, bastava que a pessoa comprasse alguma coisa e revendesse a outra, com intenção de obter lucro, sem exigência de formação qualquer. A estrutura do comércio era o que, ou onde, o vendedor pudesse carregar sua mercadoria (TEIXEIRA, 2017).

\subsection{TEORIA DA EMPRESA}

A Teoria dos Atos do Comércio, difere-se da Teoria da Empresa, a qual tem relação com 
a atividade econômica exercida pelo indivíduo. Ou seja, é quem pratica o necessário para a existência da atividade comercial (GRACIANO; JUSTI. 2017).

Destarte, importa acrescer a esta discussão, a definição da função da empresa, muito bem estampada por Coelho (2011, p. 26 e 27):

Em 1942, na Itália, surge um novo sistema de regulação das atividades econômicas dos particulares. Nele, alarga-se o âmbito de incidência do Direito comercial, passando as atividades de prestação de serviços e ligadas à terra a se submeterem às mesmas normas aplicáveis às comerciais, bancárias, securitárias e industriais. chamou-se o novo sistema de disciplina das atividades privadas de teoria da empresa. o Direito comercial, em sua terceira etapa evolutiva, deixa de cuidar de determinadas atividades (as de mercancia) e passa a disciplinar uma forma específica de produzir ou circular bens ou serviços, a empresarial.

A fim de normatizar os atos da empresa, a legislação civil brasileira de 2002, baseada na teoria italiana, adotou a Teoria da Empresa, substituindo a Teoria dos Atos do Comércio. E, dedicou livro especial à matéria, no qual distribui entre o artigo 966 ao 1.195, normas destinadas aos empresários, sociedades simples e empresárias, bem como regra o estabelecimento empresarial e seus institutos. No entanto, tal como o Código Civil Italiano, não conceituou empresa, apenas estabeleceu como empresário "[...] aquele que exerce profissionalmente atividade econômica organizada para a produção ou circulação de bens e serviços (Art. 966)", bem como definiu o que abrange o estabelecimento comercial (FARIAS, 2013).

Outrossim, vale fazer uma comparação entre a antiga "Teoria dos atos do comércio" e a "Teoria da Empresa". Se vê que, a primeira, para identificar um comerciante, baseava-se no ato comercial da atividade que exercia, o que excluía a agricultura do instituto do comércio, por exercer atividade organizada em fatores de produção, sendo considerada, portanto, ato civil, não comercial. Não obstante, a "Teoria da Empresa” engloba na identificação do empresário a forma de organização dos fatores de produção, atividade econômica a fim de produzir e circular bens e serviços. Discute-se aqui, a estrutura empresarial do exercício da atividade econômica (FARIAS, 2013).

Destarte, Machado (2003) discorre a transição do direito comercial para direito da empresa ou empresarial, baseando-se na promulgação do Código Civil Brasileiro de 2002, de maneira que a tecnologia muda o panorama econômico. Isso coloca a empresa como "centro da economia moderna", a qual produziu e produz efeitos ao desenvolvimento industrial, equiparando em igualdade as atividades econômicas de produção e de serviços.

O grande impasse dessa teoria é que não se estabeleceu um conceito jurídico para “empresa”, apesar de o Código Civil Italiano de 1942 influenciar na implantação desta. Nesse sentido, ambos, Código Italiano e Código Civil Brasileiro regularam as características das relações de trabalho, o estabelecimento comercial e a atividade do empresário. O que fez com que o legislador brasileiro repetisse o mesmo verbo em seu dispositivo, conceituando, no entanto, "empresário" e não empresa. 
Desta feita, pode-se dizer que a promulgação da Lei nº 10.406/2002 (novo Código Civil Brasileiro), foi o ponto de transição entre o Direito Comercial e o Direito Empresarial. Diante disso, o foco do tema deixa de ser o comerciante e os atos do comércio, passando assim a ser considerado a organização da atividade econômica de produção de bens e serviços exercida por profissional (MACHADO, 2003).

Para concluir, importa destacar os descritos de Hentz:

[...] dá-se tratamento à empresa como uma realidade jurídica, além da sua indiscutível importância no cenário econômico, como principal ente do processo de produção e circulação de riquezas no mundo moderno. A teoria da empresa dá guarida às formas jurídicas conhecidas, considera as relações com os seus integrantes e com o mercado, aponta as exigências para a existência válida e estabelece a natureza e o limite das obrigações transmitidas a seus órgãos, no regular (e no irregular) exercício de atividades empresariais. (HENTZ, 2010. p. 111)

Assim, nasce o Direito Empresarial, com todas as características que movem o desenvolvimento econômico de um país. Dá-se o lugar e a função ao empresário, com seu devido registro e seguimentos jurídicos, quais sejam, empresários individuais, microempresários, empresários rurais, entre outros. Contudo, o Código Civil de 2002, é então o responsável pela evolução desse ramo do direito.

Diante do exposto, verifica-se que o Direito Comercial tem acompanhado a evolução de humanidade. E como tal, outras situações e exigências tem surgido para o cenário empresarial. Visto que hoje, desde que os ideais da Revolução Francesa, os quais já introduziram uma forma mais humanizada a respeito da função da empresa, bem como hoje, ela inserida em um Estado Democrático de Direito não cabe mais respaldar-se apenas na obtenção desenfreada de lucro, deixando à parte suas responsabilidades tanto sociais, como ambientais.

\section{RESPONSABILIDADE SOCIAL DA EMPRESA}

Nesse cenário, verifica-se que o Direito Empresarial precisou evoluir para adequar-se às exigências sociais. Assim, o legislador, ao perceber que, num cenário essencialmente capitalista, a empresa passaria a concentrar-se apenas na geração de lucros, olvidando-se de sua responsabilidade para com a sociedade, bem como para com o próprio empregado ou colaborador, haveria a precípua necessidade de frear tal atitude. Isso porque inserida em um Estado Democrático de Direito a função da empresa ultrapassa a lucratividade, todavia passa a abarcar uma ampla gama de responsabilidades:

O Direito, por seu turno, é uma invenção humana, um fenômeno histórico e cultural concebido como técnica para a pacificação social e a realização da justiça. Em suma, enquanto a Justiça é um sistema aberto de valores, em constante mutação, o Direito é um conjunto de princípios e regras destinado a realizá-la. E nem sempre o Direito alcança esse desiderato, quer por não ter acompanhado as transformações sociais, quer pela incapacidade daqueles que o conceberam, e quer, ainda, por falta de disposição política para implementá-lo, tornando-se por isso um direito injusto. (CAVALIERI 
FILHO, 2002, p.59)

Dessa forma, ao se entender o Direito como algo construído diuturnamente, e que deve atender aos anseios sociais, para assim não ser considerado injusto. Nesse sentido, em função das contínuas transformações do cenário econômico, a empresa, assume responsabilidades auxiliares às contribuições sociais do Estado, assumindo assim, um novo e importante papel na sociedade. (ZAGONEL e BARACAT, 2019). Isso porque:

\begin{abstract}
O modelo econômico adotado pelo constituinte brasileiro, de fato, garante a liberdade econômica e a livre iniciativa, entretanto, impõe limites ao exercício destes direitos. Diferente dos ideais liberais clássicos, a Constituição de 1988 impõe como requisito ao direito de propriedade a observância à função social. (ZAGONEL e BARACAT, 2019, p.411).
\end{abstract}

Com isso, a empresa deixou de ser vista apenas como geração de riquezas ou lucro, mas é vista também como uma instituição social, da qual depende toda a humanidade. Isso porque a empresa é a responsável pelo emprego, produção e intermediação de mercadorias, além de ser também a origem de grande parte das receitas do Estado (MAGALHÃES, 2009). Nesse sentido:

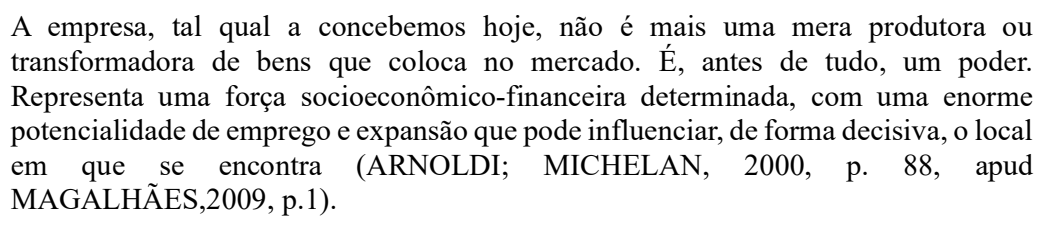

Com isso, surge a ideia de Função Social da Empresa. Percebe-se que tal concepção expressa mais que a busca pelo lucro, mas sim, a empresa, inserida na sociedade, deve intentar formas para equilibrar seus objetivos com as necessidades da comunidade. Assim, salienta-se ainda que a responsabilidade social, vai além de práticas apenas filantrópicas, mas implica essencialmente em alterações políticas internas e organizacionais da própria empresa. (ZAGONEL; BARACAT, 2018).

\title{
3.1 A EMPRESA E A LIVRE INICIATIVA
}

Como visto alhures, o Direito Empresarial evoluiu de um direito aplicado às “Corporações de ofício", instituído e regrado por particulares, para um Direito Público, instituído e aplicado pelo Estado. Isso ocorreu em função das necessidades de regulamentar as funções e responsabilidades da empresa enquanto parte do Estado Democrático de Direito.

Nesse ínterim, é pertinente recordar que no plano constitucional atualmente vigente no Brasil, há a garantia da livre iniciativa para o Direito Empresarial. Essa ideia vem da concepção liberal clássica, para a qual teoricamente não encontrariam barreiras de exercício em direitos de cunho social, preponderando a busca apenas pela lucratividade. Tal pensamento propicia ao indivíduo prerrogativas 
de exercer atividades econômicas sem quaisquer restrições do Estado (ZAGONEL; BARACAT, 2018)

Todavia, tal acepção, no ordenamento jurídico nacional, não pode ser visto isoladamente sim ser compreendido pela ótica dos demais princípios de natureza coletiva, ligados à dignidade da pessoa humana, bem como aos demais fundamentos econômicos previstos na Constituição (ZAGONEL; BARACAT, 2018). Destarte, destaca-se que:

Apesar da garantia do exercício da liberdade de iniciativa, a empresa deve preocuparse com um desenvolvimento econômico sustentável e em gerar reflexos positivos à sociedade, auxiliando o Estado na busca da justiça social e dos objetivos da República. (ZAGONEL; BARACAT, 2018, p. 412)

Por conseguinte, o Art. 170, CF, valoriza, de forma explícita, além da livre iniciativa, a valorização do trabalho, e a existência digna, em patamar de igualdade. Zagonel e Baracat lecionam: "a livre iniciativa possui um conteúdo social que supera a mera liberdade de iniciar uma atividade econômica e dela obter a remuneração do capital". Isso demonstra, a positivação da livre iniciativa representa, sim, a ausência de intervenção estatal na atividade econômica, contudo, o conjunto normativo ao qual está inserida impõe limitações, ainda que de forma subjetiva. (ZAGONEL; BARACAT, 2018).

\subsection{A EMPRESA, COMO PROPRIEDADE PRIVADA NO ESTADO DEMOCRÁTICO DE DIREITO}

Como visto, a empresa está inserida em um Estado democrático de Direito, e, por conseguinte, acaba por ter regrada suas atribuições e posses, sob essa ótica. Veja-se que:

O Estado Democrático de Direito implantado no Brasil a partir da Constituição Federal de 1988 dispõe sobre a propriedade privada de forma condicionada, atribuindo-lhe uma função social a cumprir (art.170, II, III). Assim, o sentido de propriedade, compreendido, ao longo dos séculos, como direito puramente individual, abrigado de qualquer ingerência de particulares e mesmo do Estado (notadamente a partir das revoluções burguesas) passa a sofrer uma limitação. (BARACHO; CECATO, 2016, p.115)

Torna-se necessário destacar que a função social da empresa está intimamente ligada ao constitucionalismo social. Isso porque a Constituição Federal de 88 estabelece a propriedade e sua função social como princípios formadores da ordem econômica (BARACHO; CECATO, 2016). Algumas pessoas tanto físicas como jurídicas, não sabem distinguir a questão de direito e de função social, então, destarte destacar uma afirmação, exemplificando a propriedade:

A propriedade não é um direito; é uma função social. O proprietário, quer dizer, o possuidor de uma riqueza tem, pelo fato de possuir esta riqueza, uma função social a cumprir; enquanto cumpre esta missão seus atos de proprietário estão protegidos. Se não a cumpre ou a cumpre mal, por exemplo não cultivando sua terra ou deixando sua 
casa se arruinar, a intervenção dos governantes é legítima para obrigar-lhe a cumprir sua função social de proprietário, que consiste em assegurar o emprego das riquezas que possui conforme seu destino. (DUGUIT, 1975 apud BARACHO; CECATO, 2016, p.118).

Destaca-se, nesse campo, a Lei nº 6.404/76 (Lei das Sociedades por ações) dispõe sobre a função social da empresa desde 1976:

\begin{abstract}
art.116, paragrafo único: $\mathrm{O}$ acionista controlador deve usar o poder com o fim de fazer a companhia realizar seu objetivo e cumprir sua função social, e tem deveres e responsabilidade para com os demais acionistas da empresa, os que nela trabalham e para com a comunidade em que atua, cujos direitos e interesses deve lealmente respeitar e entender; art.154, caput -[...] satisfeitas as exigências do bem público e da função social da empresa. (BRASIL, 1976 apud BARACHO; CECATO, 2016, p.116)
\end{abstract}

Assim, percebe-se que o direito de propriedade da empresa, deve ser também exercido, sob a ótica de atendimento da função social, estabelecido pela ordem constitucional vigente, ou seja, a propriedade deve ser exercida conscientemente, visando o bem comum. (BARACHO; CECATO, 2016).

\title{
3.3 FUNÇÃO SOCIAL DA EMPRESA
}

Diante do que fora até aqui explanado, verifica-se que é considerada cumpridora da sua função social a empresa que gera empregos, tributos e riqueza, contribui para o desenvolvimento econômico, social e cultural da comunidade em que atua, de sua região ou do país, adota práticas empresariais sustentáveis visando à proteção do meio ambiente e ao respeito aos direitos dos consumidores. Se sua atuação é consentânea com estes objetivos, e se desenvolve com estrita obediência às leis a que se encontra sujeita, a empresa está cumprindo sua função social; isto é, os bens de produção reunidos pelo empresário na organização do estabelecimento empresarial estão cumprindo com a pretensão do legislador constituinte (COELHO, 2012).

O princípio norteador da função social, assim como da liberdade de iniciativa, é a busca pela dignidade. Desse modo, “[...] a propriedade somente poderá ser considerada socialmente funcional quando respeitar a dignidade da pessoa humana e contribuir para o desenvolvimento nacional e a diminuição das desigualdades sociais" (GONDINHO, 2000 apud GOMES, 2006, p. 130).

Nesse sentido, nota-se que o mundo vive um momento onde as ações desempenhadas pelas empresas em prol da sociedade, são observadas constantemente. Algumas atuam de maneira séria e comprometida, porém existem situações que são julgadas como estrategistas. De acordo com Okino e Cavalcante, memoriando, Werlang Filho (2010):

Uma empresa capitalista: caracteriza-se pela busca incessante de lucros. Muitas delas, na atualidade, usam uma "maquiagem" de marketing, a saber: "fundo" social, "contribuinte" social, "responsabilidade" social ou mesmo de "empresa cidadã"; algumas promovem programas internos de interação e integração funcional, 


\begin{abstract}
"premiando" os funcionários que mais se destacam, quer com aumento na produção (produtividade) ou desenvolvimento de projetos, elaborações, invenções, etc. que venham a contribuir com o aumento da produção. Com isto, a empresa tenta passar ao cidadão a idéia de que está preocupada com a sociedade e com o desenvolvimento social, mas, na verdade, ela esconde seu verdadeiro objetivo. Esses "subsídios" à sociedade, às vezes, são tidos, por certas pessoas, como benevolências, mas na realidade servem de estímulo para que estes produzam ainda mais, gerando lucros ainda maiores. O salário que o trabalhador recebe é o preço ou expressão monetária da força de trabalho; o trabalhador também é comprado pelo capitalista por um preço que não leva em consideração suas necessidades, mas sim as relações de oferta e demanda de trabalho presentes no mercado. A única mercadoria que o trabalhador tem para negociar é a sua força de trabalho; logo, para que este não seja explorado ainda mais, tem se a alternativa de uma organização classista em torno de associações e sindicatos fortes, assim como de partidos políticos representativos, etc. para que possam representá-los eficientemente com poder de negociação e barganha. (WERLANG FILHO, 2010, apud OKINO; CAVALCANTE, 2010)
\end{abstract}

Veja-se que, mesmo com todas as exigências constantes na legislação brasileiras, algumas empresas forjam a sua função social com estímulos puramente fictícios/cadastrais. Não há, contudo, uma efetividade na realidade funcional. Nesse aspecto, atenta-se que ainda há o que se evoluir para que realmente as empresas avancem no sentido do cumprimento de sua função social, para que cumpram e se enquadrem aos ditames previstos e estabelecidos constitucionalmente.

\title{
4. SUSTENTABILIDADE: PERENE RESPONSABILIDADE DA EMPRESA
}

Outro fator deveras importante para a atividade empresarial é a questão da responsabilidade ambiental. A cada dia cresce o número de empresas que incorporam em seu dia-adia práticas visando a responsabilidade ambiental da empresa, muitas indo além do que a legislação exige. É sabido, contudo, que tais práticas, podem, muitas vezes, acarretar tanto na piora, quanto na melhora do desenvolvimento financeiro da empresa. (SOUZA, 2019). Assim, se faz necessário entender as inferências que circundam tais circunstâncias, bem como explicitar o papel da empresa na questão sustentabilidade.

\subsection{A EMPRESA E O MEIO AMBIENTE: UMA PREOCUPAÇÃO FUNDAMENTAL}

No Brasil, os movimentos ambientalistas emergem da década de 70, quando iniciaram a formação de entidades e associações com a preocupação de proteger a natureza, incluindo meio ambiente e animais. A Conferência das Nações Unidas realizada em Estocolmo, em 1972, passou a pautar o movimento ambientalista brasileiro, com o surgimento de legislações que previam o controle da poluição decorrente da atividade industrial. (ROCHA, LIMA e ROCHA, 2018).

Schiavo e Bussinguer (2020, p. 85) destacam que "1981, o Brasil editou a Política Nacional do Meio Ambiente que deu uma nova roupagem à legislação ambiental no país e começou a 
utilizar as políticas públicas para a proteção do meio ambiente". Assim, paulatinamente, novos aspectos e responsabilidades foram sendo incorporados às empresas, que precisaram se adaptar a este novo cenário que se moldava à sua frente.

Ao se analisar o cenário atual, verifica-se que "em nosso ordenamento jurídico, o direito ao meio ambiente ecologicamente equilibrado, constitui-se de materialidade caracterizadora de norma fundamental, qual seja o direito ao ambiente ecologicamente equilibrado contemplado pelo artigo 225 da Constituição Federal" (ROCHA; LIMA; ROCHA, 2018, p. 4).

Nesse prisma, em contraponto, como já abordado alhures, há a previsão constitucional do direito à livre iniciativa, tendo por titular o direito da empresa, a qual pode perceber óbice às suas atividades, a questão socioambiental. (ROCHA; LIMA; ROCHA, 2018). Isso porque:

as decisões tomadas pela empresa impactam não somente seus custos, mas, também, as percepções dos consumidores a respeito de suas atitudes. Isso significa que a "demanda" também pode ser afetada conforme a tomada de decisão por parte da empresa. Neste caso, pode-se afirmar que os consumidores, ao entenderem que a empresa possui preocupação social, podem preferir consumir produtos e serviços desta empresa em relação aos produtos e serviços de suas concorrentes. (SOUZA, 2019, P. 5)

Nesse cenário, surge para o Direito Empresarial, a responsabilidade de novos direcionamentos de sua atividade:

[...]a necessidade de desenvolver formas de crescimento econômico pautados na sustentabilidade, a fim de prestigiar, tanto o direito ao meio ambiente ecologicamente equilibrado, quanto o direito a livre iniciativa, de modo a se evitar, tanto problemas oriundos de impactos ambientais decorrentes da atividade desenvolvida pela empresa, quanto obstar o desenvolvimento da atividade empresarial que demanda a mesma proteção jurídica conferida ao meio ambiente, por ser a responsável pela promoção de interesses sociais e pelo crescimento da economia. (ROCHA; LIMA; ROCHA, 2018, p. 5).

Visto dessa forma, percebe-se que o lucro não deixa de ser objetivo perseguido pela empresa, mas deixa sim de ser o único objetivo. Isso porque a empresa hoje não pode descuidar de sua inexorável responsabilidade ambiental (GONÇALVES; NISCHI, 2019). Ademais, tais autores ainda elucidam que as empresas:

[...] que não buscam maximizar seu lucro não sobrevivem por muito tempo, ou seja, não é possível afastar-se de tal objetivo por muito tempo sob pena de fechamento da empresa. Portanto, seja por uma ou outra tendência doutrinária, fato é que a empresa interage com a sociedade na qual se encontra de forma que, perseguindo direta $\mathrm{e}$ inexoravelmente seu objetivo primordial de lucro ou optando, espontaneamente, por redistribuição direta de renda na forma de inclusão social ou preservação ambiental; incorrerá, ainda que, em objetivo de segundo plano, na realização de ação com reflexos socioambientais que poderão, sim, ser mais ou menos efetivos, eficazes e, mesmo eficientes para que se atinjam os desideratos empresariais, sociais e ambientais. (GONÇALVES; NISCHI, 2019, p.209-210).

Destarte, dessa forma, surge para as empresas, a Responsabilidade Socioambiental da 
Empresa (RSAE), na qual a empresa precisa se preocupar tanto com o bem-estar social, como com as questões de sustentabilidade. Empresas que demonstram tais preocupações, tanto de engajamento ambiental, quanto social, tem ganho destaque perante seus investidores, clientes, fornecedores e sociedade em geral, o que repercute no aumento da rentabilidade da empresa (GONÇALVES; NISCHI, 2019).

\title{
4.1 RELAÇÃO DO DIREITO EMPRESARIAL E O LICENCIAMENTO AMBIENTAL
}

Como visto, a ideia de empresa, na atual ordem Constitucional, abarca uma visão que transcende a mera obtenção do lucro, mas corrobora para a construção de uma sociedade livre, justa e solidária.

\begin{abstract}
Antes de ser alçado à categoria de direito fundamental, o direito ao meio ambiente ecologicamente equilibrado fora totalmente sobrepujado pelo homem que se encontrava imbuído apenas do anseio de desenvolver-se tecnológica, científica e economicamente. Maior exemplo disso foi a Revolução Industrial, momento a partir do qual fora deflagrada completa mudança do panorama social, e especialmente, da relação entre a forma e a matéria, considerando o exercício de maior controle do homem sobre a natureza. Pois, foram desenvolvidos mecanismos extremamente eficientes que alteraram os modos de produção e propiciaram a mais absoluta ruptura com os padrões de vida anteriormente estabelecidos pelo homem, doravante, completamente reconfigurados. (ROCHA; LIMA; ROCHA, 2018, p. 2).
\end{abstract}

Nesse enfoque, em nossa sociedade que está permanentemente:

\begin{abstract}
Não por acaso que se mostra imprescindível o desenvolvimento de uma abordagem altamente crítica capaz de unir o plano social, o econômico e o ambiental para que a livre iniciativa, um dos pressupostos caracterizadores da ordem econômica, se concretize dentro de sua máxima lastreada em assegurar a todos a existência digna, de tal modo que mesmo sendo inquestionável que o direito ao meio ambiente ecologicamente equilibrado é "direito constitucional impositivo", bem como "direito das presentes e das futuras gerações" 18 , não se despreze a livre iniciativa em nossa ordem econômica, já que além de diretriz de todos os demais princípios elencados no artigo 170, funciona como propulsora do desenvolvimento social e econômico do país. (ROCHA, LIMA E ROCHA, 2018, p. 12-13).
\end{abstract}

Cabe destacar também a questão do Licenciamento Ambiental para as empresas. Nesse aspecto, deve-se entender que:

O Licenciamento Ambiental se constitui em instrumento de Estado para fazer a mediação entre os interesses da coletividade e os interesses de empreendedores desejosos de construir infra-estrutura ou desenvolver produtos industriais, guardando relação direta com a emergência da nova esfera pública apresentada por Habermas (1984). Requisito legal que antecede a instalação de atividades poluidoras, as que utilizam recursos ambientais ou com potencial de causar degradação ambiental, o Licenciamento Ambiental é um instrumento que busca proteger o meio ambiente de danos irreversíveis ou identificar arranjos através dos quais os danos ambientais possam ser evitados, mitigados e/ou compensados. (Souza e Jacobi, 2011, apud, Schiavo e Bussinguer, 2020, p. 89) 
Diante disso, insta compreender que o Licenciamento ambiental tem a finalidade de avaliar os possíveis impactos que aquela atividade ambiental poderá causar ao meio ambiente, bem como de investigar a atividade que será instalada, a fim de, com base nos dados coletados, prever possíveis desastres ambientais. (SCHIAVO; BUSSINGUER, 2020). Nesse ínterim:

\begin{abstract}
O processo administrativo de Licenciamento Ambiental é composto por três fases distintas, sejam elas, Licença Prévia, Licença de Instalação e Licença de Operação. Essas etapas devem ser cumpridas por aquele que deseja um parecer do órgão responsável para liberação de qualquer atividade econômica que envolva alguma alteração no meio ambiente. Cumpre salientar que, entre essas etapas, pode ser exigida uma Audiência Pública para que seja explicitado todo o procedimento da atividade para a sociedade e demais interessados no processo (SCHIAVO; BUSSINGUER , 2020, p.97).
\end{abstract}

Funciona, portanto, como um poder de polícia para fiscalizar as atividades potencialmente poluidoras, com um controle pelo Estado. Assim, além de uma preocupação da própria empresa, deve ser uma preocupação do Estado, como meio de controle, visando o Desenvolvimento Sustentável, com a capacidade de conciliar o crescimento e a expansão de novas atividades empresariais com equilíbrio ambiental (SCHIAVO E BUSSINGUER, 2020).

\title{
5 ANÁLISE DO DIREITO EMPRESARIAL HOJE - UM PROGNÓSTICO
}

\section{NECESSÁRIO}

Diante do cenário evolutivo pelo qual o Direito Empresarial passa, verifica-se que, há grande destaque no que tange à conjuntura em que se abandona a ideia apenas de geração de lucro e se interpela a condição de outras responsabilidades da empresa, tanto social, como ambiental. Dessa forma, ressalta-se que:

\begin{abstract}
A instituição do Estado social impôs, no entanto, duas consequências jurídicas da maior importância para a organização das empresas. De um lado, o exercício da atividade empresarial já não se funda na propriedade dos meios de produção, mas na qualidade dos objetivos visados pelo agente; sendo que a ordem jurídica assina aos particulares e, especialmente, aos empresários, a realização obrigatória de objetivos sociais, definidos na Constituição. (COMPARATO, 2005, p. 296, apud, VERONESE e OLIVEIRA,2016, p. 12)
\end{abstract}

Veja-se que essa nova circunstância acarretou na ruptura de paradigmas, bem como na alteração basilar da compreensão e função da empresa enquanto parte da sociedade civil organizada. Nesse sentido, Chaves (2014, p.2) leciona:

No âmbito da ciência jurídica tais discussões ocorrem numa conjuntura de amplas modificações do Direito Privado, a partir das quais se reconstroem muitos de seus paradigmas. Frente a este cenário, alguns de seus institutos tradicionais sofrem transformações na perspectiva de uma abordagem à luz das Constituições, diante da existência de uma maior confluência de interesses privados e públicos a norteá-los. 
Assim, vislumbra-se que cada época foi pertinente para o aperfeiçoamento do que ora se intitula "Direito Empresarial". A cada tempo a sociedade foi moldando esse ramo do direito, para que atendesse às suas necessidades e particularidades, fazendo prevalecer a ideia de justiça. Pode-se afirmar, portanto, que os juristas "tendo sensibilidade para perceberem os anseios da justiça, empenham-se em ajustar o Direito a essas exigências antes mesmo do legislador, idealizando novas fórmulas jurídicas" (CAVALIERI FILHO, 2002, p.2).

\subsection{EVOLUÇÃO DO CONCEITO DE JUSTIÇA NA HISTÓRIA DO DIREITO}

\section{EMPRESARIAL}

Ao se pensar que "Direito e Justiça são conceitos que se entrelaçam, a tal ponto de serem considerados uma só coisa pela consciência social. Fala-se no Direito com o sentido de Justiça e viceversa" (CAVALIERI FILHO, 2002, p.2), reflete-se que num Estado Democrático de Direito, não há espaço para pensamentos apenas patrimonialistas e fragmentados. Há, de certa forma, a superação da liberdade irrestrita de atuar submetida à autonomia da vontade, em razão e nos limites impostos pelo ordenamento jurídico, em especial, nesse sentido, da função social da empresa. (VERONESE e OLIVEIRA, 2016, p.2)

Nessa perspectiva, ao se considerar toda a trajetória do Direito Empresarial, que, como supracitado, perpassou de um direito consuetudinário, para a "Teoria dos Atos do Comércio", na qual a ideia de direito era voltada à pessoa do comerciante, bem como à "teoria da Empresa", na qual se principiou uma maior abertura de entendimento da ideia de justiça, ao que se tem hoje como representação de "Direito Empresarial" aduz-se que tal como o direito em geral, o Direito Empresarial não é matéria estanque, não há como entendê-lo, tampouco dissociá-lo do conceito de "Justiça", circunstância que o acompanha no decorrer dos tempos. Sendo assim:

[...] fazendo um paralelo do direito comercial conforme foi construído no decorrer dos séculos com o Direito Empresarial com o está positivado hoje, podemos perceber que o direito de modo geral sempre regulou a vida em sociedade, assim, o Direito Empresarial regula as atividades comerciais que são praticamente a estrutura econômica do país, pois faz circular o dinheiro e cria postos de trabalho. (SOARES; CAMPOS, 2019, p.5)

Salienta-se que o Direito Empresarial está em constante evolução e deve sempre atender aos anseios do interregno temporal ao qual está inserido. Nesse sentido:

Isso acontece porque a idéia de Justiça engloba valores inerentes ao ser humano, transcendentais, tais como a liberdade, igualdade, fraternidade, dignidade, equidade, honestidade, moralidade, segurança, enfim, tudo aquilo que vem sendo chamado de direito natural desde a antiguidade. (CAVALIERI FILHO, 2002, p.2) 
Diante disso, torna-se relevante também destacar:

Na idade contemporânea não é mais possível empreender apenas vislumbrando o lucro, por isso a necessidade de criar mecanismos para alavancar os negócios e concomitante respeitar o meio ambiente, atinar sobre a responsabilidade social com relação aos colaboradores e toda a sociedade que de alguma forma se beneficia com a empresa (SOARES e CAMPOS, 2019, p.4).

Percebe-se, com isso, que justamente a concepção de justiça, hoje intrinsicamente ligada ao direito empresarial, proporciona o entendimento de que o compromisso da empresa perpassa a mera função social, atinge precipuamente uma responsabilidade social. Isso porque, "no ramo do direito empresarial é possível apontar como princípios gerais mais importantes a liberdade de iniciativa, a liberdade de competição e a função social da empresa”. (SANTOS, 2013, p. 9, apud, VERONESE; OLIVEIRA, 2016, p.9-10).

\title{
5.2 REGULAMENTAÇÕES DO DIREITO EMPRESARIAL NO SÉCULO XXI
}

Como visto, mesmo a ideia de justiça se modifica no decorrer dos tempos, nem tudo que era considerado justo em determinada sociedade continua a sê-lo em outros períodos históricos. Assim, é mister, portanto, que se compreenda que:

\begin{abstract}
A responsabilidade social empresarial é de suma importância, pois abarca todos os ramos de atividade, não apenas as grandes corporações, mas também as empresas de pequeno e médio porte, assim como as empresas estatais e suas subsidiárias, pois quando se atua de forma correta, com critérios idôneos, toda a coletividade se beneficia (SOARES e CAMPOS, 2019, p.3).
\end{abstract}

Hoje, o Direito Empresarial, está pautado fundamentalmente, além dos ditames da Constituição Federal, também no Código Civil, no Código Comercial, no Código de Defesa do Consumidor, entre outros. Contudo, a cada dia surgem novas necessidades e perspectivas, às quais esse ramo do direito deve também abarcar. Como é o caso da questão da compliance, para o Direito Empresarial, para a qual a organização empresarial deve responder com eficiência ao gerenciamento da empresa. Necessário se faz compreender que "a palavra compliance vem do inglês "to comply", que significa seguir regras, instruções, normas, diretrizes ou simplesmente responder a um comando. O compliance pressupõe adesão e respeito a normas e regulamentos" (SOARES; CAMPOS, 2019, p.14).

Nesse sentido, pertinente é o conceito trazido por Manzi e Coimbra (2013) apud Ribeiro e Diniz (2014 p.3): 'É um conjunto de regras, normas, procedimentos éticos e legais que, uma vez definidos e implementados, guiarão a conduta da instituição no mercado em que atua, bem como a 
postura de seus colaboradores". (Tradução nossa).

No Brasil, a lei 12.846/2013 (Lei Anticorrupção ou Lei da Probidade Empresarial) é uma amostra das tentativas de regulamentação desse novo conceito de Empresa. Ademais, ressalta-se que:

A empresa ética não explora seus colaboradores, não paga propina para os compradores de seus produtos, respeita seus fornecedores e não comete crimes ambientais. Nessa toada é preciso ter normas claras de condutas internas na empresa, para que todas as pessoas envolvidas na atividade estejam afinadas aos regramentos que levam a uma prática condizente com as normas morais e éticas (SOARES; CAMPOS, 2019, p.15).

Destaca-se, ainda que:

Em face da dinâmica da economia capitalista, definiu-se no Brasil, especialmente a partir da Constituição da República Federativa do Brasil, promulgada em 1988, o seu conceito de democracia, pautada não apenas no modelo econômico liberal e nem apenas no modelo econômico social, mas dialogando entre os dois padrões, objetivando proporcionar maior benefício a todas as classes sociais, razão consagradora do Estado Democrático-Social. Dentre as alterações advindas da nova posição, destaca-se a dignidade da pessoa humana em detrimento da postura exclusivamente patrimonialista adotada anteriormente (VERONESE; OLIVEIRA, 2017, P.7).

Assim, sabe-se que cada vez mais o mercado, com destaque ao mercado consumidor, exigirá das empresas um comportamento ético, adequado, com busca do lucro de maneira sustentável e racional.

\subsection{DESAFIOS E COMPROMISSOS DA EMPRESA}

Como já abordado, a ética empresarial surge como característica imprescindível para o sucesso e fixação da empresa. A ideia de ética empresarial, está alicerçada, principalmente no conceito de dignidade da pessoa humana, com preocupações que englobam circunstância que vão além do aspecto econômico (SIQUINEL; CHAVES; BALDISSERA, 2017, p. 2-3). Nesse sentido:

\footnotetext{
Ver na Ética um caminho para promover as empresas aos olhos da opinião pública não é fantasia, uma miragem. Uma empresa que põe em primeiro lugar os seus clientes, que respeita o meio ambiente, que reconhece ter uma responsabilidade social, que se preocupa com a vida cultural dos seus trabalhadores, que está atenta a todos os que, direta ou indiretamente, têm alguma relação com ela, melhora a sua imagem e tira disse benefícios de diversa índole e, entre eles, benefícios econômicos. Tornou-se evidente para os empresários e gestores que a empresa não se relaciona apenas com as pessoas que têm a ver diretamente com sua produção do ponto de vista econômico (LUCCA, 2009, p. 338, apud SIQUINEL; CHAVES; BALDISSERA, 2017, p. 2).
}

A sociedade consumidora está cada vez mais atenta às atitudes da empresa. Siquinel, Chaves e Baldissera (2017, p. 6) lecionam que:

Ao agir eticamente com o governo, a empresa não abrirá brechas para a corrupção, evitando que dinheiro público seja utilizado para beneficiar indevidamente políticos e funcionários públicos. Ao agir eticamente com seus funcionários, a empresa cria uma cultura interna capaz de motivar seus colaboradores a, por exemplo, deixar de desperdiçar materiais, evitando assim maiores custos. Ao agir eticamente perante seus 
fornecedores, a empresa cria um vínculo de confiança mútua capaz de lhe trazer benefícios econômicos com a manutenção de preços dos insumos por mais tempo, seleção dos melhores produtos, e concessão de melhores condições de pagamento. Ao agir eticamente com o consumidor, a empresa cria uma identidade confiável, uma relação de fidelidade e fortalece a figura do consumidor como a mais importante no processo de desenvolvimento econômico

Com isso, demonstra-se indubitável a necessidade de a empresa agir com ética em todos os aspectos que circundam a atividade empresarial. Ademais, Veronese e Oliveira (2017, p.14) exploram que esse imperativo ético das empresas, está intrinsicamente ligado à sua função social, sendo forma de contribuir para o progresso social. Esses autores ainda explicitam que a empresa, com tal postura ética, repercutem em diversas maneiras de "geração de renda, de oportunidades de trabalho para o desenvolvimento de talentos individuais e na preservação do meio ambiente, neste último caso visando assegurar qualidade de vida para as gerações futuras" (VERONESE; OLIVEIRA, 2017, P.14).

Ademais, "nesse contexto, a empresa assume extrema relevância social, pois contribui decisivamente para o funcionamento da vida social, na medida em que responsável por produzir riquezas, distribuir renda e possibilitar a arrecadação de impostos (VERONESE; OLIVEIRA, 2017, P.14).

Destarte, sabe-se que a Constituição de 88 , apregoa a livre iniciativa como valor a ser respeitado. Todavia, mesmo esse conceito deverá ser observado pelas empresas como a:

[...] conjunção de diversos dispositivos constitucionais, que, de algum modo, com eles se relacionam, como, por exemplo, os que protegem a propriedade privada, a função social da propriedade, a defesa do consumidor, o livre exercício da profissão e a proteção do trabalho (ARAÚJO; NUNES JÚNIOR, 2014, p.563, apud ZAGONEL; BARACAT, 2018, p.9).

Observa-se que tal pensamento justamente propicia uma visão macro, do conceito de livre iniciativa. Ressalta-se que nada, no Direito Brasileiro pode ser visto de maneira individualista e fragmentada. Consoante defendido por Cavalieri Filho (2002, p. 65) "se a finalidade do Direito é a realização da Justiça, a finalidade da Justiça é a transformação social; a construção de uma sociedade justa, livre, solidária e fraterna, sem preconceitos, sem pobreza e sem desigualdades sociais".

\section{CONSIDERAÇÕES FINAIS}

Diante de todo o estudo até aqui realizado verificou-se que o Direito Empresarial tem papel de destaque na regulamentação da sociedade como um todo. E para isso galgou árduos patamares, acompanhando a evolução da humanidade e remodelando-se a cada etapa da civilização.

Reconhece-se que tal evolução está longe de ter-se como finalizada, eis que novos desafios e exigências surgem diuturnamente, todavia compreende-se que em relação à concepção 
inicial, houve considerável progresso. Tem-se, contudo, a consciência de que para se alcançar o desenvolvimento social, com prevalência do princípio da dignidade da pessoa humana, a empresa, como parte operante desse contexto, tem papel primordial, como elemento de transformação da sociedade.

Desta forma, o Direito Empresarial vem a ser a ligação entre o interesse público e o interesse privado, cabendo a ele regulamentar e pacificar eventuais divergências, sempre prevalecendo o interesse da coletividade.

\section{REFERÊNCIAS BIBLIOGRAFICAS}

AZIZ, Tamine. Teoria dos atos de comércio X Teoria da Empresa. 2017. Disponível em: $<$ https://cadernodatata.com.br/teoria-dos-atos-de-comercio-X-teoria-da-empresa/> Acesso em: 23 set. 2020.)

BARACHO, Hertha Urquiza; CECATO, Maria Aurea Baroni. Da Função Social da Empresa à Responsabilidade Social: Reflexos na Comunidade e no Meio Ambiente. Direito e Desenvolvimento, João Pessoa, v. 7, n. 2, p. 114-128, 2016. Disponível em: $<$ https://periodicos.unipe.br/index.php/direitoedesenvolvimento/article/download/320/300/> Acesso em: 20 out. 2020.

BENSOUSSAN; BOITEX. Manual de Direito Empresarial. $1^{\text {a }}$ ed. Salvador/BA: Editora juspodivm, 2018, pdf. 3285_Miolo-manuais p conc-Bensoussan-Boitex-Manual de Direito Empresarial.pdf disponível em:

$<$ https://www.editorajuspodivm.com.br/cdn/arquivos/9547c48dcf8af9776710223986937410.p df $>$ Acesso em: 17 set. 2020.

CAVALIERI FILHO, Sergio. Direito, Justiça e Sociedade. Revista da EMERJ, Rio de Janeiro, 2002. Disponível em:

$<$ https://www.emerj.tjrj.jus.br/revistaemerj_online/edicoes/revista18/revista18_58.pdf $>$

Acesso em: 25 out. 2020.

CHAVES, Vinicius Figueiredo. Uma Análise Crítica Do Fenômeno Empresa - Dos Interesses Exclusivos Privatistas aos Institucionalistas Publicistas: Criando Valor Compartilhado.

Revista Publica Direito, Florianópolis, 2014 Disponível em: http://www.publicadireito.com.br/artigos/?cod=2a60eed05079970d. Acesso em: 17 ago. 2020.

COELHO, Fábio Ulhoa. Curso de direito comercial: direito de empresa. Vol. 1. 16 edição. São Paulo: Saraiva, 2012.

Paulo: Saraiva, 2011.

Manual de direito comercial: direito de empresa. 23. ed. - São

FARIAS, Ricardo Rodrigues. Teoria da empresa e o empresário individual. 2013. Âmbito Jurídico. revista 112. Disponível em: $<$ https://ambitojuridico.com.br/edicoes/revista-112/ateoria-da-empresa-e-o-empresario-

individual/\#: :text=O $\% 20 \mathrm{C} \% \mathrm{C} 3 \% \mathrm{~B} 3 \mathrm{digo} \% 20 \mathrm{Civil} \% 20 \mathrm{Brasileiro} \% 20 \mathrm{de}$,de $\% 20 \mathrm{bens} \% 20 \mathrm{ou}$ 
\%20de \%20servi\%C3\%A7os> Acesso em: 23 set. 2020.

GOMES, Daniela Vasconcellos, 2011. Função Social do Contrato e da Empresa: aspectos jurídicos da responsabilidade social empresarial nas relações de consumo. Desenvolvimento em Questão, Editora Unijuí. Ano 4, n. 7, jan./jun, 127-152. 2006. Disponível em: $<$ https://www.revistas.unijui.edu.br/index.php/desenvolvimentoemquestao/article/view/124> Acesso em: 17 out. 2020.

GONÇALVES, Everton das Neves; NISHI, Lisandro Fin. Responsabilidade Socioambiental Empresarial (Rsae): Lucros e Bem-Estar Sob a Ótica do Princípio da Eficiência EconômicoSocial (Pees). Percurso - ANAIS DO VIII CONBRADEC, vol.02, n.29, Curitiba, 2019. pp. 196-224. Disponível em:

$<$ http://revista.unicuritiba.edu.br/index.php/percurso/article/viewFile/3495/371371924> Acesso em: 25 out. 2020.

GRACIANO Karoline de Andrade; JUSTI, Douglas - Uni Santa Cruz - Centro Universitário. 2017 v. 4 n. 4 (2014): IV Jornada de Iniciação Científica e de Extensão Universitária Disponível em: <https://santacruz.br/revistas/index.php/JICEX/article/view/1049> Acesso em: 23 set. 2020 .

HENTZ, Luiz Antonio Soares. A TEORIA DA EMPRESA NO NOVO DIREITO DE EMPRESA. Revista Em Tempo, [S.1.], v. 5, mar. 2010. ISSN 1984-7858. Disponível em: $<$ https://revista.univem.edu.br/emtempo/article/view/191>. Acesso em: 23 sep. 2020.

MACHADO, Daniel Carneiro. O Novo Código Civil Brasileiro e a Teoria Da Empresa. DC Machado - Belo Horizonte:[sn, 200, 2003 - academia.edu. Disponível em: $<$ https://d1wqtxts1xzle7.cloudfront.net/3245372/doc13.pdf?response-contentdisposition=inline \%3B +filename\%3DO_Novo_Codigo_Civil_Brasileiro_Ea_Teoria.pdf\&Ex pires $=1600891017 \&$ Signature=Tys3QIQGJyu3NSe5pjBq T04 fRfFe2m12N0UyT25FZq1wS QRGSUidrCMMIXLDplmqCMeFoHPLxKCJDMIrmNZRNxMOIAJgTWYS4gnN9IZI6pT7zmDpuOXFYiR8e0NJ4dZXxD8qLoJMS6PlhaFLb66JDqinmeWe 37 tautr8EYRr7 5ruHbMrr7PONAQm G-1un9qLST3nUr7igPm3JyIW1h3-

Spq0FHW SCiQMerQtZouOw61 r NYuIscenY5mYMR0ekB9TPI4u3rHIpz7EVe7fWR7D DtqrWeo -hd1j3bb3-ruLUKiZm QCBkTRFJjI3jLWkg38HGm48INeriYg_\&Key-PairId=APKAJLOHF5GGSLRBV4ZA> Acesso em: 28 set. 2020.

MAGALHÃES, Rodrigo A. A função social e a responsabilidade social da empresa. In:

Revista Magister Direito Empresarial, Concorrencial e do Consumidor. v. 28, p. 10-23, 2009, p.03.Disponível em <https://revistas.newtonpaiva.br/redcunp/wpcontent/uploads/2020/05/PDF-D13-11.pdf> .Acesso em 25 out.2020

MIRAGEM, Bruno Nubens Barbosa. Do Direito Comercial ao Direito Empresarial. Formação histórica e tendências do Direito brasileiro. 73484-304583-1-PB.pdf. Revista da Faculdade de Direito da UFRGS. 2004. Disponível em:

$<$ https://www.seer.ufrgs.br/revfacdir/article/download/73484/41374> Acesso em 17 set. 2020.

OKINO, Michelle Yumi Felipe; CAVALCANTE, Caio César Carvalho, 2010. Desemprego e Exclusão Social: Princípios Fundamentais em Xeque? Disponível em: $<$ http://www.cchla.ufrn.br/cnpp/pgs/anais/Arquivos\%20GTS\%20\%20recebidos\%20em\%20PDF/DESEMPREGO\%20E\%20EXCLUS\%C3\%830\%20S 
OCIAL\%20PRINCIPIOS\%20FUNDAMENTAIS\%20EM\%20XEQUE.pdf> Acesso em: 19 out. 2020.

RIBEIRO, Marcia Carla Pereira, DINIZ, Patrícia Dittrich Ferreira. Compliance: Una Perspectiva Desde La Ley Brasileña No $12.846 / 2013$. Revista Eurolatinoamer Icana De Derecho Administrativo, Santa Fé, 2014. Disponível em:

https://bibliotecavirtual.unl.edu.ar/publicaciones/index.php/Redoeda/article/view/4638 17067. Acesso em 29 set. 2020.

ROCHA, Débora Cristina de Castro da; LIMA, Daniela Lopes da; ROCHA, Edilson Santos da. O Meio Ambiente Ecologicamente Equilibrado e o Direito de Livre Iniciativa Pautado na Atividade Empresarial Dentro da Ordem Econômica. Revista Percurso, v.3. n26, Curitiba, 2018. Disponível em:

http://revista.unicuritiba.edu.br/index.php/percurso/article/view/3151. Acesso em 22 out. 2020 .

SCHIAVO, Victor Rizo; BUSSINGUER, Elda Coelho de Azevedo. O licenciamento ambiental como política pública e o poder das empresas. Revista Opinión Jurídica, Medellín, 2020. Disponível em: <http://www.scielo.org.co/scielo.php?pid=S1692$25302020000100083 \&$ script $=$ sci_abstract\&tlng=pt $>$. Acesso em: 22 out.2020.

SIQUINEL, Roberto; CHAVES, Ulisses Lyrio; BALDISSERA, Leonardo. A ética empresarial na sociedade de consumo. Revista Percurso, Curitiba, 2017. Disponível em: http://revista.unicuritiba.edu.br/index.php/percurso/article/view/2601. Acesso em 06 out. 2020.

SOARES, Marcelo Negri; CAMPOS, Maria Gisela. Compliance Na Realização Da Função Social Da Empresa. Revista Percurso, v.1, n²8, Curitiba, 2019. Disponível em: http://revista.unicuritiba.edu.br/index.php/percurso/article/view/3416\#: :text=COMPLI ANCE\%20NA\%20REALIZA\%C3\%87\%C3\%830\%20DA\%20FUN\%C3\%87\%C3\%83 O\%20SOCIAL\%20DA\%20EMPRESA,Marcelo\%20Negri\%20SOARES\&text=Este\%20artigo\%20tem\%20por\%20escopo,no \%20\%C3\%A2mbito\%20do\%20direito\%20empresarial. Acesso em 17 ago.2020.

SOUZA, Carlos Aurélio Mota de. Responsabilidade Socioambiental Empresarial (Rsae): Lucros e Bem-Estar Sob a Ótica do Princípio da Eficiência Econômico-Social (Pees). Revista Percurso, v.2, $\mathrm{n}^{\circ}$ 29, Curitiba, 2019. Disponível em: http://revista.unicuritiba.edu.br/index.php/percurso/article/view/3495. Acesso em 22 out.2020.

TEIXEIRA, Antonio. Jurisway Sistema Educacional on line, 2017. Disponível em: $<$ https://www.jurisway.org.br/v2/dhall.asp?id dh=18541 $>$ Acesso em: 23 set. 2020.

VERONESE, Eduardo Felipe; OLIVEIRA, Francisco Cardoso. A Atividade Empresarial E Sua Função Social: A Efetivação Dos Direitos Fundamentais. Revista Unicuritiba, v.1, n. 18, Curitiba, 2016. Disponível em:

http://revista.unicuritiba.edu.br/index.php/percurso/article/view/1732. Acesso em: 17 ago. 2020.

ZAGONEL, Marina; BARACAT, Eduardo Milléo. Responsabilidade Social E Função Social Da Empresa À Luz Do Princípio Da Livre Iniciativa: Análise Do Projeto “Especiais Do Super 
Especial" Para Contratação De Pessoas Com Deficiência, Desenvolvido Pela Rede De Supermercados Festval. Revista Percurso, Curitiba, 2018. Disponível em:

http://revista.unicuritiba.edu.br/index.php/percurso/article/view/3150. Acesso em 06 out. 2020. 